\title{
Active and Passive Voice Constructions by Indonesian Student Writers
}

\author{
Nurenzia Yannuar \\ State University of Malang, Malang, Indonesia \\ Ida Ayu Shitadevi \\ State University of Malang, Malang, Indonesia \\ Yazid Basthomi \\ State University of Malang, Malang, Indonesia \\ Utami Widiati \\ State University of Malang, Malang, Indonesia
}

\begin{abstract}
Author stance, which echoes authors' attitudes, personal thought, and feeling within the text, can be revealed through preference of voice construction. This study aims at examining the quantitative data of active and passive voice construction used in the English Department of State University of Malang students' theses, as well as exploring the implication arising from the issue. The data in this descriptive qualitative study is taken from a corpus of English Department undergraduate theses written in 2011 to 2013. The corpus data and the frequency of both voice constructions of selected Biber's (2004) stance verbs are calculated using Ant.Conc 3.2.4 corpus software. Findings show that the frequency of active voice construction is higher than that of the passive, as much as $64.8 \%$ out of 3901 tokens of the stance verb suggest, expect, show, predict, report, believe, hope, allow are in active voice. The most frequent stance verb in active voice constructions is the verb show, while that in passive voice is the verb expect and the least frequent in both voice constructions is the verb predict. This study suggests that the frequent active voice construction found in Indonesian undergraduate theses resembles English native author's writing style. This fact may indicate Indonesian student author's determination to be acknowledged internationally.
\end{abstract}

Index Terms - voice construction, corpus study, stance, academic writing

\section{INTRODUCTION}

Active and passive voice constructions are interchangeably used in academic and non-academic writing for different purposes, for example passive voice constructions is used to execute special discourse functions due to its marked voice (Biber et al., 2003) such as creating distance between writer and the text mostly found in scientific paper (Baratta, 2009). However, numerous studies on passive have been conducted from various spectrums to obtain thorough understanding on both passive and active voice constructions.

Passive voice construction is mainly used in method section to get rid of personal whims and fancies, and thus obtain impersonality and universality of the research (Ahmad, 2012). Ahmad found that $70 \%$ of passive was implemented in method of Medical and Natural Science articles; however, the use of active voice construction was higher in other sections. It can be assumed that the style of English native writer is to deploy more passive, while the examination of written discourse production of non-native speaker showed that non-native English writer displayed complications and tendency of avoiding passive voice, though they have undertaken many years of L2 learning and use (Hinkel, 2004; Espinoza, 1997).

On the other spectrum, Baratta (2009) investigated the stance derived from the passive voice as it was an advantageous tool to indicate the writer's feeling, which underlined the speaker as the subject focus, not as the rearobject. Passive voice to indicate author's stance is supported by the semantic class of words, that each word conveys different meaning and purpose. Biber (2004) gave new sight on how stance verbs vary from different kinds of genre, including academic writing. He indicated that there was a general shift in cultural norms that speakers and writers were more willing to express stance in recent periods than in earlier historical periods.

Different perspectives of passive voice and marking stance evoke new research focusing on the usage of active voice and passive voice in academic writing to show the author stance. This research is interested in scrutinizing active and passive voice construction used in the English Department of State University of Malang students' theses. The core proposals are to find what makes it different to express ideas in active or passive construction, and the implications of using the two constructions for academic writing. In researching such phenomena, corpus-based study is conducted to enable the researcher to create generalization and convincing conclusions upon the phenomena (Baker, 2006). Corpus 
based study allows data restriction on the selected data only and the patterns and trends will be shown thoroughly. The result also contributes to the improvement of the teaching of writing, and it can be regarded as a new encouragement for students to express their ideas in active or passive interchangeably.

\section{LITERATURE REVIEW}

\section{A. Stance Verb and Semantic Classification}

Referring to Biber (2004), it is important to consider the grammatical system to analyze the authorial stance: (semi)modals, adverbials, and complement clause construction. Those specific grammatical devices are distinguished and specified into semantic domains. However, due to the focus of the present study on active and passive voice construction, the verb element control is the most appropriate, followed by that-complement clause and to-complement clause. Table 2.1 shows the verb stance of each semantic class by Biber (2004):

TABLE 2.1

STANCE VERB (BIBER, 2004)

\begin{tabular}{lll}
\hline That- Complement Clause & Non-factive/communication & Imply, report, suggest, etc \\
\cline { 2 - 3 } & Attitudinal & Anticipate, expect, prefer, etc \\
\cline { 2 - 3 } & Factive & Demonstrate, realize, show, etc \\
\cline { 2 - 3 } & Likehood & Appear, Hypothesize, Predict, etc \\
\hline \multirow{2}{*}{ To- Complement Clause } & Speech act & Urge, Advise, Convince, etc \\
\cline { 2 - 3 } & Mental/cognition & Believe, Learn, Pretend, etc \\
\cline { 2 - 3 } & Desire/intent/decision & Aim, Hope, Decide, etc \\
\cline { 2 - 3 } & Modality/cause/effort & Allow, Leaver, Order, etc \\
\cline { 2 - 3 } & Likehood & Happen, Seem, Appear, etc \\
\hline
\end{tabular}

\section{B. Voice Construction and Academic Writing}

Passive voice construction can be useful to write descriptive passages as well as give instructions. In contrast to passive construction, using active voice will background the process or the description, the focus of stage is lost and the emphasis shifts to the agent (Swales \& Feak, 2008). Nevertheless, Beason and Lester (2003) argue that passive voice can lead to a dull style because it does not stress action and hides the agent doing an action. Tendency to show politeness through employing passive construction may occur, yet providing reason might be necessary. However, when the doer of the action is unimportant or unknown, the passive voice is appropriate.

In general, instructional detail of using specific voice is not properly addressed in certain degree. This may become the result of the traditional separation of teaching grammar and teaching writing (Hinkel, 2004). The teaching of grammar covers the use of tenses and voices without relating those to the academic writing, while, in writing instruction, the use of voice varies depending on the purpose of the author stance.

It is important to note recent change in English native speaker's academic writing style, in which writers are encouraged to use more active voice rather than passive. Regardless the debate over improper use of active voice, we can underline the change in the teaching of writing (i.e Hartley, 2008; Smith, 2008; and Norris, 2013)..

\section{Voice Construction and Authorial Voice}

Academic writing is regarded as a tool to communicate authors' critical thinking and projecting the content. Moreover, it becomes a useful tool to gain credibility by showing an identity invested with individual authority, displaying confidence in the judgment to their ideas (Hyland, 2002b). One of the ways writers can embody themselves in readers' consciousness is through pointing out the use of I to show the author's credibility, commitment to the words presented, and as well as to engage with the readers (Hyland, 2002a).

Taking into account of the authorial voice construction, it can be drawn that employing author pronoun means conveying active voice construction within the sentence. In other words, the debate over authorial voice, whether or not to project the author in the text and engage with readers, will be in the same light as choosing active or passive construction. The choice is seen as a depiction on how authors take stance.

\section{Types of Passive Voice Construction}

Active construction is the most common, while passive is less common and used for special discourse functions; the passive reduces the importance of the agent of the action and fulfill other discourse function (Biber, et al., 2003). There are several forms of passive, mostly are constructed in form of the auxiliary be and an -ed participle. However, passive can also be formed with auxiliary get, which is called the get-passive.

Passive construction occurs either as short passive or long passive. Long passive contain a by-phrase which specifies the agent of the action, however there are also exception to the use of by to govern the agentive phrase, i.e the room was permeated with gas and he is known to me (Coetzee, 1980). In principle, the long passive can be replaced by an active clause with the same meaning, yet it will be less appropriate than the passive voice (Biber et al., 2003). Biber et al.'s (2003) principals for choosing long passives in writing include: (1) the information-flow, in which preference for presenting new information at the end of a clause; (2) end-weight, in this case the agent does not hold up the processing 
of the rest of the clause; and (3) the long passive place initial emphasis on an element of the clause, which is the topic or theme. In other words, long passive construction allows the object agent to have less attention from the readers and somehow lack of responsibility.

Meanwhile, short passive is when the agent is not specified. According to Biber, et al. (2003), the short passive is a useful device in academic writing because it gives the status of topic to the direct object of the corresponding active clause. The sense of objective detachment also appears by employing the non-agentive passive. However, the short passive should not be applied when the agent is actually present, as Coetzee (1980) believed that short passive should not be thought of as derived from the long; short passive should be treated as agentless sentences. What is interesting about this agent device, according to Coetzee, was that it operated as though the derivation of the short passive were via agent deletion from the long passive. It creates such understanding that this kind of process allows the readers, as well as the author, to hide and rediscover the hidden agent. Hence, this agentless passive particularly occurs more frequently in serious scientific writing than in any other genre (Coetzee, 1980).

\section{E. Language Typology and Culture}

Passive in the context of language typology will be the distinction between topic-prominent language and subject prominent language ( $\mathrm{Li} \&$ Thompson, 1976). The basic organization of topic-prominent language is the terms of topic and comment; while that of subject-prominent language is the subject and predicate. East Asian language belongs to topic-prominent language and Indo-European language belongs to subject-prominent language. In relation to passive voice construction, it is common to find passive construction in subject-prominent language; while, in topic-prominent language, the passive construction only serve small portion or even not at all. Li and Thompson (1976) argue that this is because topic- prominent language allows the noun phrase as the topic sentence without changing the form of verb. In other words, the sentence sounds passive while the verb construction does not show change of passive, as in subjectprominent language the verb undergo a change in format.

These separate typologies contribute to the different rhetoric style of both languages, because topic-prominent language focuses on the topic, while subject- prominent language focuses on the relationship between subject and the predicate. The difference and the impact it arises were analyzed by Basthomi (2006). The study investigated introductory section of research articles written by Indonesian authors, and the study suggested that Indonesian authors have weak bargaining power due to their failure to accomplish several expectations of international editors or reviewers. Considerably, the L1 of the international editors are English, which is subject-prominent; hence, problematic issues variously occur.

Cultural expectation around academic discourse, different rhetoric, and approach to authority which non-native English speaker do not possess, then becomes the main concern (Starfield, 2007). Basthomi (2006) also mentioned that Indonesian writers of English had no problem with mastering linguistic code in English like phonological, morphological, lexical, and syntactic features of level; yet, acquisition of cultural properties, including rhetorical conventions are still hard to attain.

\section{THE CORPUS: C-SMILE}

C-SMILE (Corpus of State University of Malang Indonesian Learners' English) is a collection of 124 undergraduate theses from English Department (and the number is accumulating along the submission of the theses) totaling around 1,587,059 words. It epitomizes academic writing of theses from English pedagogy, English linguistics, and English literature across years starting from 2011 to 2013. C-SMILE encapsulates various methods of research like qualitative research, quantitative research, classroom action research, research and development, and mixed research methods. However, the distribution of each method is not equal in every year and discipline. Moreover, each thesis may comprise different number of chapters; while one thesis can consist of five or six chapters, others can contain only four chapters. These various distributions provide us with access to the desired area of the corpus and thus help us to be more focused.

The corpus data were collected from the library of the Faculty of Letters, State University of Malang, Indonesia, in view of the criteria set as follows. First, the data should be in the form of undergraduate theses. Second, the data are written in English. Third, the data are produced by Indonesian writers. The data satisfying the criteria were accessed in the form of soft files of $p d f$ and/or $d o c$. files. For the purpose of analysis, we relied on AntConc 3.2.4w (Windows) 2011 version as a tool to work on the concordance properties.

As a corpus-based project, the present study, by nature, is inductive which is aligned to qualitative design (Litosselitti, 2010). However, the present research also implements a quantitative method, like frequency information on the occurrences of particular linguistic phenomena. As such, as a corpus study, this study amalgamates both quantitative and qualitative methods.

\section{FINDINGS AND DisCUSSION}

\section{A. Findings}

Concerning the first proposal to decode the different use of active and passive voice construction, the distribution of frequency of active and passive voice are presented in Table 4.1 below. 
TABLE 4.1

FREQUENCY OF ACTIVE AND PASSIVE VOICE

\begin{tabular}{|c|c|c|c|c|c|c|}
\hline \multirow[t]{2}{*}{ No } & \multicolumn{3}{|l|}{ Active } & \multicolumn{3}{|l|}{ Passive } \\
\hline & Semantic Class & Verb & frequency & Semantic class & Verb & frequency \\
\hline 1 & factual/certainty & show & 1600 & attitudinal & Expect & 555 \\
\hline 2 & non-factive/ communication & suggest & 302 & factual/certainty & Show & 439 \\
\hline 3 & Cognition & believe & 255 & non-factive/ communication & Suggest & 207 \\
\hline 4 & modality/cause/effort & allow & 137 & modality/cause/effort & Allow & 55 \\
\hline 5 & attitudinal & expect & 90 & cognition & Believe & 49 \\
\hline 6 & desire/intention/decision & hope & 60 & communication/ speech act & Report & 35 \\
\hline 7 & communication/ speech act & report & 45 & desire/intention/decision & Hope & 22 \\
\hline 8 & likehood & predict & 37 & likehood & Predict & 13 \\
\hline \multicolumn{2}{|c|}{ TOTAL } & & $\begin{array}{l}2526 \\
64.8 \%\end{array}$ & TOTAL & & $\begin{array}{l}1375 \\
35.2 \%\end{array}$ \\
\hline
\end{tabular}

Active voice constructions occur more frequent than passive voice construction, as it appears $64.8 \%$ and $35.2 \%$, respectively. The total word tokens of the eight stance verbs: show, suggest, believe, allow, expect, hope, report, predict, in both constructions are 3901 tokens comprising 2526 tokens of active voice construction and 1375 tokens of passive voice construction.

Show

The verb show, semantic class of factive or certainty, hints 2039 times from the total 3901 tokens in active and passive voice construction. Active voice construction of show is applied in the form of present tense, past tense, and present perfect. Excerpt (1) below illustrate examples of active voice construction of show.

Excerpt (1)

(a) rs analysis from the second re-administration shows that $38 \%$ of the multiple-choice items have inadeq he roleplay cards. (AE-2013- edu.txt)

(b) Then, the researcher tried to show the idea and design of the role-play cards. She a (BN-2013-edu.txt)

(c) changed the material. Figure 3.7 in the left side shows the artificial bills before the validation which (EM-2013edu.txt)

(d) (ing a Recount Paragraph. The result of the study showed that the use of Mr. Bean videos through writing (K2011-edu.txt)

(e) In the first meeting of cycle 1, it was showed that the class was still in poor situation (SIC) (HM-2011-edu.txt)

Data number (1a) and (1b) are the type of occurrence that dominates in data corpus. Data number (1c) gives impression that the word show functions as lexical to point out or give explanation about something. In this example, it functions to point out that Figure 3.7 (data 1c) has artificial bills before the validation. Data number (1d) is written in the past tense form which is mostly found in Data Findings because the form is generally used to report event that has been conducted by the researcher. Sentence in data number (1e) is an example of grammatical error in which meaning is understood as active voice construction. The first error is that in passive voice construction, the verb must be written in perfect form, which is shown; instead of showed. The second error is that the meaning of the sentence will be correct when it is written in active voice construction by eliminating the modality was. Hence, this data is put into occurrence of active voice construction.

In this study the verb show always dominates the lexical choice, particularly in findings and discussion sections. Appearing in as many as 1600 active voice occurrences from 3901 tokens, the verb show frequently functions as lexical item to explain or prove fact and information, defining the truth and existence of something. As its main function is to explain and prove facts, the subject and object focus is considerably prominent. The active voice construction allows the revealing of the subject to the reader, hence it helps the reader absorb the explanation on particular subject's action of informing some findings, directly to the main idea. Maintaining stance verb show in active voice construction creates directness impression to the reader and it help the reader to follow the author's thought.

Meanwhile, the use of passive voice construction of verb stance show is mainly maintained to aid in textual cohesion (Baratta, 2009). As it is purposely aid in textual cohesion, the subject being explained is located backward, for instance excerpt number (2a): “... from the observation, it was shown that the students could actively..." This sentence can be rephrased into direct and concise explanation by constructing it into active voice: “. $\ldots$ the observation shows that the students could actively...". By constructing active voice, the readers do not spend more time to decode the impersonal subject it, which refer to the previous statement; thus the key idea is easily captured. What is written in the first order or what becomes a subject is deemed important than that in the object position. The flow of information focuses first to the subject position, and it is a fruitful method to maintain the directness attitude.

Excerpt (2)

(a) because, from the observation checklist, it was shown that the students could actively participate in t (NP-2013edu.txt)

(b) When the play fails, the displeasure is clearly shown in their expressions, whereas in the book they on (FA-2012lit.txt)

(c) ng the quality maxim in English baby milk slogans shown on Indonesian TV advertisements. Then, the resear (SC-2013-lit.txt) 
(d) help students in creating some conversations, as shown in Picture 3.1 Picture 3.1 Example of Writing Act (AW2013-edu.txt)

(e) a dictionary. Second, the expressions which are showed in movies, are various and easy to understand. S (SIC) (AS-2013-edu.txt)

Predict

It hints only 50 times from the total 3901 tokens, both in active and passive voice construction. The verb predict is the last dominating verb in that complement clause classification; appear for 50 times from 3243 tokens. It is the last dominating verb from over all active and passive voice constructions.

Excerpt (3)

(a) e the questionnaire and interview. The researcher predicted that collecting data would take 2 weeks. Yet, ti (CS2013-edu.txt)

(b) difficult word, he does not stop reading. He only predicts the meaning through the context given. He does no (AS2013-edu.txt)

Data number (3a) show the author standpoint, while in data number (3b) verb predict is applied in the context of describing or explaining a particular event in the study.

Passive voice construction of predict is applied in the form of present tense and past tense. It covers only 13 occurrences out of the total number of 50 predict occurrences. Excerpt (4) below shows examples of passive voice construction of expect:

Excerpt (4)

(a) ted in the activity of pair or group work. It is predicted that when the students share their opinion or id (AD2013-edu.txt)

(b) diction. Dependent variable is the variable being predicted (Sprinthall, $1994: 25)$. In th (RS-2012-edu.txt)

Data number (4a) shows that the predication is stated by the author, while data number (4b) is stated by an expert, indicating a quotation done by the author.

The other unique finding is the verb stance predict, which occur the least for both active and passive voice construction. The active voice construction hints 37 times and the passive voice construction hints 13 times. The stance verb predict characterizes semantic features of like-hood. For academic research, showing like-hood is not appropriate even though some predictions are possibly to take place in particular section of the paper. In C-SMILE corpus, stance verb predict stated by the author is low. It usually appears in the description of the research process, statement, or as part of discussion without being necessarily stated by the author.

Expect

Passive voice construction of expect is applied in the form of present tense and past tense. It covers 555 hints out of the total number of 645 expect tokens, or as high as $86 \%$ of data corpus of expect. Examples of passive voice construction of expect are given below:

Excerpt (5)

(a) 1.4 Significance of the Study This study was expected to have beneficial contribution for the English (AI-2012Education.txt)

(b) he inclusion program of elementary schools. It is expected that the product can be used as one of the altern (AR2012-Edu.txt)

(c) iency. By knowing the result of this study, it is expected that the book publisher and writer would receive (DNR2012-Edu.txt)

(d) alang. Through this media, the learners were expected to master the reading skill. Acquiring descry (GL-2013edu.txt)

Looking at the high gap between the active and passive voice construction; it is clear that verb expect is mostly applied in passive form. The dominance of the occurrences also portray the author's standpoint toward the result of the study, students, teacher, including the material. Data number $(5 a),(5 b),(5 c)$, and (5d), shows the expectation toward the study, which is always found in the chapter of significance of the study, toward the material, result of the study, and the students respectively.

The active voice construction only occurs 99 times, while the passive voice construction occurs 555 times. The authors' preferences to express expectation in passive voice construction is then the authorial stance. The passive voice construction of verb stance expect is frequently non-agentive passive. Whereas, the subject doer of such expectation, varies from teacher, advisor, students, research object, and the author themselves. The deletion of subject doer creates irresponsible hopes; consequently it allows the author to take blame on unnamed agent and the readers do not obtain thorough understanding. Even if the object-focus is deemed necessary for many authors, yet agentless passive is incapable of revealing people's expectations toward the study. Despite the demand for upholding research objectivity, giving credits to the people involved in the research does not diminish its objectivity. Furthermore, the use of passive voice construction of expect is typical of Indonesian writing.

The frequent occurrence of active voice construction has similarity with Ahmad (2012) that in several parts of Medical and Natural Science research articles cover high frequency of active voice construction. Introduction and discussion section of Medical and Natural Science research articles have higher active voice construction; while in 
method and result have higher passive voice construction. However, the difference is that in this corpus based study the total of active voice construction $(64.8 \%)$ is higher than that of passive voice construction, while the active voice in Ahmad's study covers only $30 \%$, less than the passive voice construction. The field of study possibly caused the difference of this occurrence. Method and result sections of Medical and Natural Science research articles contribute significant and crucial information about scientific processes. The core of the articles is the method in which section must be impersonalized, so different doers still produce the same result and conclusion. Moreover, the language of scientific research does not accumulate implications (Ahmad, 2012).

However, Ahmad's study also showed that active voice construction appeared high in the sections other than method and result sections. It indicates that to deliver idea, in which focus is not the process, active voice is frequently used. In academic text like thesis writing, the focus of the study is not only on the method and result, but also discussion, introduction, and literature review. Hence, the language use is also different from scientific language, which allows interpretations, emotional association (Ahmad, 2012), and more strategies to engage with the readers (Hyland, 2005).

Despite the low frequency of passive voice construction in this study, the passive voice is fruitful in maintaining explanation about process, giving instruction and description. The focus of the stage becomes the emphasis rather than the doer, and the process or the description will be foreground (Swales \& Feak, 2008). This is supported by great number of passive voice construction in research method and findings section in this study. However, it is not in the same light as Swales and Feak (2008) when the author comes to expressing ideas and projecting judgments. Active voice construction is more appropriate because the emphasis is not a process, but rather the action. Passive voice construction can hide or delete the doer of the action and the focus is not the action anymore; thus, it can lead to a dull style of writing (Beason \& Lester, 2003). The use of passive voice construction should not be over generalized and applied in almost all sections, though objectivity is deemed to be important. The dominating number of active voice construction becomes the evidence in this study, and also the study by Ahmad (2012).

\section{B. Discussion}

The high frequency of active voice construction found in undergraduate students' theses implies that the style of EFL students, to some extent, have resembled that of English native writer, mainly in academic writing, as they apply more active voice construction (see Ahmad, 2012). Interpretative reasons for EFL students show resemblance of English native writer include: 1) whether EFL students are simply following what they have been taught by teachers both in Indonesian and English settings, be it preference for active or passive voice construction; or 2) EFL students prefer the easiest way to express their idea and engage the reader with arguments, thus the authors, the EFL students, become acknowledgeable.

The first interpretation is that EFL students are simply following what they have been taught, although there is a mixture between knowledge EFL students have been taught by teachers, particularly in Indonesian setting, and exposures of English academic writing by teachers and lecturers, particularly from international journals. The fusion of the background knowledge and the exposure is best represented by the high number of passive stance verb expect, which actually is rather typical of Indonesian rhetoric style.

The L1 of the students is Indonesian, a language which falls under topic-prominent language category. Its construction of grammar relation focuses on the topic-comment rather than on the subject-predicate relation (Li \& Thompson, 1976). Due to the free positioning of noun phrase as topic sentence without changing the form of the verb, in topic-prominent language (Coetzee, 1980), the confusion of constructing passive then may occur as EFL students must construct passive voice in language which typology is subject-prominent.

On the other hand, EFL students are exposed to language that focuses on subject-predicate grammar relation. Thus with such topic-prominent language typology, it becomes problematic when students produce sentences expressing information, ideas, and knowledge. Consequently, the mixing Indonesian rhetoric style in English setting occurs as a high number of passive verb stance expect dominates the passive voice construction. In a wider context, Indonesian authors subconsciously write English prose seasoned with Indonesian language flavor. It is then supporting the Basthomi (2006) findings, in which he claimed that Indonesian research article still hold the Indonesian flavor of rhetoric. With the implementation of widely range of agentless passive voice, it is apparent that Indonesian style of rhetoric is rather indirect (Basthomi, 2006).

Another effect of this problematic decision making in expressing ideas, is that some passive voice constructions mainly function as tools to maintain cohesion rather than showing stance. Baratta (2009) suggests that passive voice can also aid in textual cohesion, and projecting author stance. In his study, however, the data was taken from three essays written by three undergraduate students that compromise aspect of their language and literacy learning. Their essays successfully reflected the author's stance through the passive voice construction. It was due to the emphasis of author background information by placing the object into subject position. Again, this is topicalization which emphasizes the author's information, and thus, very effective to reveal the author stance. What becomes the concern now is that this topicalization is somehow effective depending on the text type, though it may be the same academic writing topic. Therefore, the passive stance is quite erratic in this study; and consequently, the use of passive voice construction is mainly successful to maintain cohesion of the text.

The second interpretation is that students prefer the easiest way to express their idea and engage the reader with their arguments that enable the author to be acknowledged. Implementing active voice construction to assert claim and take a 
definite position seems approachable because it does not require regular or irregular verb form. Acquiring irregular verb comes in later stage in acquisition order, and also performing regular verb is the most difficult for L2 learners (Ellis, 1997). The use of active voice construction ranges variously from introduction section, literature review, and discussion section. Furthermore, these sections become the primary section where students dominantly express their idea, show judgment, and lead the readers into interpretation. In regards to this purpose, active voice construction is more preferable than passive voice construction. The study by Hinkel (2004) and Espinoza (1997) also suggest that passive voice construction for non-native speaker of English is rather difficult to master even after so many years of learning L2. Advanced non-native speaker students might have difficulty with conventionalized passive voice. They simply chose to avoid using such complex verb phrase construction like passive voice. Moreover, non-native speaker students had difficulty to use passive voice correctly and construct it in appropriate contexts.

The high number of active voice construction found in undergraduate students' theses that to some extent have resembled that of English native writer, creates such a thought that Indonesian authors possess a desire to gain 'position' in international community. It means that Indonesian authors are mainly in determination to maintain desirably writing style to elevate their contribution in academic writing, exclusively in international domain. Gaining position internationally, presumably, can help Indonesian contribute their culture in wider context. One method to gain position, and thus become acknowledgeable by international community is through subscribing to the rhetorical expectations of the representatives of international discourse community (Basthomi, 2006). According to Basthomi (2006), journal editors and reviewer hold the power to judge and choose whose work is worth publishing; hence, submission to the rhetoric of English academic writing comes to be essential.

However, the process of acquiring rhetoric style of English native writer is always the key problem for non-native English writer, particularly Indonesian. The findings suggest that Indonesian authors are found hard to diminish their rhetorical style while working the English academic text. As a result of maintaining cohesion between sentences with the same ideas, the length of sentence composition, then, indicates how Indonesian authors tend to prolong the deliberation; not striking the key point directly. Thus, it affects readers' engagement toward the text that, later on, also affect the value of author's stance. Nevertheless, Indonesian author, particularly EFL students, shows determination of upholding the expectation of international academic discourse community. This determination also manifests in the teaching of writing for EFL learners particularly.

The teaching of writing for EFL learners can promote an activity of sensitizing the rhetoric style of English writer and integrate the teaching of grammar with writing to yield a better writing product that enables Indonesian authors, particularly EFL learners, to gain a better position internationally. Surprisingly, writing guidelines for Indonesian have been projecting Anglo-centric textbook style (Basthomi, 2006). Nevertheless, the recent study and Basthomi (2006) suggest that Indonesian authors are still facing problems in building a rhetorical competence allowing them to get their writings easily published internationally.

The order of the high frequency of stance verb show, suggest, expect, and the last order of the least frequent stance verb predict indicate the semantic features of general academic writing, particularly English thesis writing. Stance verb show is resemblance of certainty and factual statement, stance verb suggest is that of communication strategy or nonfactive, stance verb expect is that of attitudinal of the author, and stance verb predict is that of like-hood or prediction. The frequency representation of stance verbs applied in the texts explains how the authors project their idea, attitude, and feeling; hence, stance and identity are portrayed. Writer's lexical, syntactic, and semantic choice within the writing helps construct identity (Ivanic 1994, 1995, 1998 as cited in Baratta, 2009).

The number of verb stance occurring in this study, both in active and passive voice construction, is surprisingly a showcase for the changing trend across registers, particularly in academic prose; while according to Biber (2004) academic prose infrequently uses stance devices. The finding of this study can be a new resource to confirm that academic prose, particularly in education, linguistics, and literature, in recent years has increasingly applied various stance devices. However, a thorough comparison could not be conducted on Biber's comparison on four registers periodically since 1650 until 1990, as well as to the findings of the study on academic prose, particularly in medical prose. Hence, this study aids only on verifying the increasing use of stance device in academic prose and it indicates that in recent periods authors are more willingly to express stance.

This also implicates that authors today are more open to the reader, in the sense that author engages the readers more persuasively into his/her study. The engagement of author-reader is a result of the author's effort to project his/her stance, and thus, influence the reader. The engagement is a fruitful tool for authors to make their studies, shared knowledge, as well as influences becomes acknowledgeable and present in the readers' mind. It is possible due to the struggle of the authors to pull the readers into arguments, force their attention, and guide them into interpretations (Hyland, 2005). Interpretation is a crucial point in academic writing in which circumstance of variation in interpretation among readers, as well as between readers and authors, is possible to occur. Interpretation links with decoding meaning of non-agentive passive voice construction, because intuitions and context comprehension of the readers determine the success of how the idea of the author should be understood. Non-agentive passive voice construction appearing to say nothing, but it hints a great deal as such construction suggest indirect claim to deleted agent (Coetzee, 1980). Thus, it is apparent that the engagement vis-à-vis the author's work expressing stance is essential to build the mutual understanding. 
The high and low frequency of stance verbs which are represented by the stance verb show, expect, and predict in academic writing, especially thesis writing of English pedagogy, linguistics, and literature showcase several features of: projecting facts, author's attitude, and less predictive. Projecting facts reflects the author's confidence in conveying more factual data and statement; thus evoke the reader's trust towards the study. Projecting author's attitude, which is represented by passive stance verb expect, reflects the indirectness and quite "irresponsible" for providing unclear information. This is due to the majority of the non-agentive passive found in expect occurrences. Deemphasizing and deleting important agent becomes less appropriate attitude since acknowledging people for their expectation, reaction, and opinion toward the study are deemed important. Moreover, it is typical of Indonesian writing since producing passive voice construction in correct context is relatively problematic for non-native English writer. Academic writing specifically thesis writing should not project any prediction that resembles uncertainty of the author, for it controverts the feature of presenting factuality. Future activities are rarely employed by the author to create diplomatic, defensive, and cautious stance (Swales, 1990).

\section{CONCLUSION}

The higher frequency of active voice construction (64.8\%) than the passive voice construction $(35.2 \%)$ shows that in a determination to explain, prove facts or information, define the truth and existence of something, active voice construction becomes a fruitful device. Active voice construction creates directness impression to the reader, and it helps the reader to follow the author's thought. While passive voice construction is fruitful to project process, methods, and giving instructions, both constructions become productive devices in academic writing, as long as they are not overgeneralized in every section of the academic writing. The dominant usage of active voice construction becomes an indicator that Indonesian authors' writing style has become more English native writer alike. Therefore, it shows that Indonesian authors are determined to improve their position in international discourse community. Several weaknesses of Indonesian author may still exist; however, this should be encouragement for instructors to guide EFL students to become better authors. Hence, it supports the improvement of Indonesian author's position internationally.

The order of the eight stance verbs in active and passive voice constructions indicate the features of academic writing by their different semantic classes. It appears that the order of the stance verb show and suggest dominates the active and passive voice construction. The passive stance verb is dominated by stance verb expect, and the least frequent stance verb is predict. Therefore, the frequent order of the stance verbs shows that the objectives of academic writing, especially thesis writing, are projecting facts, showing author's communication strategy, and projecting the attitude of the author, as well as other people's, toward his/her study in general.

\section{ACKNOWLEDGMENT}

This work was supported by a grant provided by the State University of Malang's LP2M (Research and Development Center) and DIKTI (Directorate General of Higher Education, Ministry of Education and Culture, the Republic of Indonesia). The research concentrates on corpus building currently focused on academic written discourse. The research has also been made possible with the help of our two research assistants: Lely Tri Wijayanti and Nuan Ifga Guswenda. Yet, upon no point should those aforementioned individuals and parties be deemed responsible for any remaining flaws; all are due to the researchers themselves.

\section{REFERENCES}

[1] Ahmad, J. (2012). Stylistic features of scientific English: A study of scientific research articles. English Language and Literature Studies 2.1, 47-55.

[2] Baker, P. (2006). Using corpora in discourse analysis. Continuum: London/New York.

[3] Baratta, A. (2009). Revealing stance through passive voice. Journal of Pragmatics 41, 1406-1421.

[4] Basthomi, Y. (2006). The rhetoric of research article introduction written in English by Indonesians. Unpublished Dissertation. Malang: State University of Malang.

[5] Beason, L., \& Lester, M. (2003). A commonsense guide to grammar and usage. Boston: Bedford/ St.Martin.

[6] Biber, D., Concord, S., \& Leech, G. (2003). Longman student grammar of spoken and written English. Harlow, Essex: Pearson Education Ltd.

[7] Biber, D. (2004). Historical patterns for the grammatical marking of stance. Journal of Historical Pragmatics 5.1, 107-136.

[8] Coetzee, J. (1980). The rhetoric of the passive in English. Linguistics 18, 199-221.

[9] Ellis, R. (1997). Second language acquisition. New York: Oxford University Press.

[10] Espinoza, A. (1997). Contrastive analysis of the Spanish and English passive voice in scientific prose. English for Specific Purposes 16.3, 229-243.

[11] Hartley, J. (2008). Academic writing and publishing: A practical handbook. New York: Routledge.

[12] Hyland, K. (2002a). Authority and invisibility: Authorial identity in academic writing. Journal of Pragmatics 34, 1091-1112.

[13] Hyland, K. (2002b). Options of identity in academic writing. ELT Journal 56.4, 351-358.

[14] Hyland, K. (2005). Stance and engagement: A model of interaction in academic discourse. Discourse Studies 7.2, 173-192.

[15] Hinkel, E. (2004). Tense, aspect, and the passive voice in L1 and L2 academic text. Language Teaching Research 8.1, 5-29.

[16] Li, C. N. \& Thompson, S. A. (1976). Subject and topic: A new typology of language. In C. N. Li (ed.), Subject and topic. New York: Academic Press, 459-489. 
[17] Litosseliti, L. (2010). Research method in linguistics. New York: Continuum.

[18] Norris, C. (2013). Academic writing in English. Helsinki: University of Helsinki.

[19] Shitadevi, I.A. \& Yannuar, N. (2013). The use of active and passive voice constructions to reveal stance: Corpus-based study on English department students' academic writing. Proceeding of the 1st ELITE Conference, Vol (1): On Linguistics and Literature. Malang: Maulana Malik Ibrahim State Islamic University of Malang in cooperation with Naila Pustaka Inc.

[20] Smith, K. (2008). Academic writing and theological research: A guide for students. Johannesburg: The South African Theological Seminary Press.

[21] Starfield, S. (2007). New directions in student academic writing. In J. Cummins \& C. Davidson (eds.), International handbook of English language teaching. New York: Springer, 875-890.

[22] Swales, J. \& Feak, C. B. (2008). Academic writing for graduate students. Ann Arbor: The University of Michigan Press.

[23] Swales, J. (1990). Genre analysis. Cambridge: Cambridge University Press.

Nurenzia Yannuar, a lecturer at State University of Malang, Indonesia, earned her Bachelor degree from Brawijaya University, Malang, East Java, and Master's degree in Linguistics from Ohio University, USA.

Ida Ayu Shitadevi is an associate researcher of C-SMILE Project, English Department, Faculty of Letters, State University of Malang.

Yazid Basthomi is Professor in applied linguistics, English Department, Faculty of Letters, State University of Malang. He chairs the departmental research group of Discourse Studies currently working on C-SMILE (Corpus of State University of Malang Indonesian Learners of English).

Utami Widiati is Professor in TEFL, English Department, Faculty of Letters, State University of Malang. She received her Master's from the University of London and Ph.D. from Monash University. 